\title{
FILOSOFIA DA ARTE E ARTE DE FILOSOFAR. ARTE, LINGUAGEM E RELIGIÃO EM FICHTE E SCHELLING (1807-1812)
}

\author{
Federico Ferraguto* \\ federicoferraguto@yahoo.it
}

RESUMO Este trabalho desenvolve aspectos da controvérsia entre Fichte e Schelling em relação aos elementos estéticos, linguístico-filosóficos e da filosofia da religião de ambos, que é foco das "Investigações sobre a liberdade humana de Schelling”, assim como das exposições da doutrina da ciência e da ética do Fichte tardio (1810-1813). As divergências entre Fichte e Schelling não envolvem apenas problemas especulativos, mas sim variadas implicações e consequências dos seus sistemas filosóficos, que podem ser destacadas por uma análise da função da analogia nos dois autores. A analogia é uma figura que agrega a estética, a filosofia da linguagem e a filosofia da religião nos dois autores; ela é um significante que põe o problema do significado, ou seja, põe o problema da relação entre finito e infinito (Schelling) e da relação entre saber absoluto e saber particular (Fichte). Essa relação vai ser investigada a partir de algumas passagens das "Investigações" de Schelling (\$2); num segundo momento, será analisada a função do conceito de analogia e de símbolo nesse contexto (\$3); e, no final, a diferente compreensão da Igreja como símbolo do absoluto na "Filosofia da arte" de Schelling e na "Doutrina moral" fichtiana de 1798 e 1812 (\$4).

Palavras-chave Fichte, Schelling, Analogia, Filosofia da linguagem, Filosofia da religião, Filosofia transcendental, Estética, Doutrina da ciência, Absoluto.

* Pontifícia Universidade Católica do Paraná (PUCPR). Artigo recebido em 06/11/2014 e aprovado em 29/08/2015. 
ABSTRACT This paper develops elements of the controversy between Fichte and Schelling regarding aesthetics, philosophy of language and philosophy of religion starting from Schelling 's "Inquiry on human freedom" and Fichte's late presentation of the "Wissenschaftslehre" (1810-1813). The polemics between Fichte and Schelling is not just a speculative one, but it involves different implications and consequences of their philosophical systems, which can be deepened through an analysis of the role of analogy by the two authors. Analogy is a figure that combines aesthetics, philosophy of language and philosophy of religion; it is a significant that puts the problem of meaning, i.e., puts the problem of the relationship between finite and infinite (Schelling) and the relationship between absolute and factual knowledge (Fichte). This relationship will be investigated starting from some passages of the "Inquiry on human freedom" (\$2); then the function of the concept of analogy and symbol in this context will be analysed (\$3) and, at last, a different understanding of the church as a symbol of the absolute in "Schelling's Philosophy of art" and Fichtes's "System of ethics" of 1798 and $1812(\$ 4)$.

Keywords Fichte, Schelling, Analogy, Philosophy of language, Philosophy of religion, Transcendental philosophy, Aesthetics, Science of knowledge, Absolute.

\section{Da filosofia primeira à filosofia da religião}

A controvérsia entre Fichte e Schelling começa, explicitamente, a partir de $1800 .{ }^{1}$ A publicação, em 1809, das "Investigações sobre a liberdade humana" de Schelling abre uma nova fase nesta polêmica, cujos elementos fundamentais tornam-se evidentes na exposição fichtiana da doutrina da ciência de 1810, e nas reflexões seguintes que Fichte realiza até 1813. É nestes anos que a avaliação crítica da filosofia de Schelling encontra a reflexão sobre a relação entre liberdade e necessidade e entre finito e infinito, que aparece também no escrito de Schelling de 1809.

A filosofia primeira, e em particular uma diferente compreensão do absoluto, de sua relação com a manifestação (Erscheinung) e, mais em geral, uma diferente avaliação das tarefas e da essência da filosofia transcendental, parecem ser dominantes na disputa entre os dois filósofos nos primeiros dez 
anos do século XIX. Mas as divergências entre eles envolvem também as variadas implicações, os variados aspectos e consequências aparentemente secundárias de seus sistemas filosóficos, como o problema da introdução no estudo da filosofia ou a interpretação da relação entre história e especulação. ${ }^{2}$

A distância que separa Fichte e Schelling, a qual, ao mesmo tempo, aproxima-os, torna-se evidente quando se considera uma diferente função da figura retórica da analogia na apresentação das características fundamentais da ciência filosófica. A analogia, que nos dois autores agrega a estética, a filosofia da linguagem e a filosofia da religião, é um significante que põe o problema do significado, ou seja, põe o problema da relação entre finito e infinito (Schelling) e o da relação entre saber absoluto e saber particular (Fichte). Em ambos os casos, o problema da analogia irá sempre envolver a explicitação das potencialidades simbólicas da finitude. Mas é apenas aparentemente que se trata de um assunto exclusivamente estético ou linguístico-filosófico. A questão da analogia envolve, portanto, uma reflexão que se coloca no nível da filosofia primeira e da filosofia da religião. De fato, em Fichte e em Schelling, uma concepção diferente da linguagem, bem como da possibilidade de doar uma forma a algo que é percebido imediatamente (arte, estética), envolve uma diferente compreensão da condição inter-humana dessa própria forma; ou seja, uma diferente compreensão das estruturas da comunidade humana que vai recebê-la. Isso se encontra, em Fichte e Schelling, na reflexão sobre o conceito de Igreja (comunidade) e do cristianismo como manifestação realizada do absoluto na história.

Nesse sentido, uma compreensão multifacetada da polêmica entre Fichte e Schelling deve juntar a filosofia primeira, a filosofia da linguagem (também a estética) e a filosofia da história. Investigarei, a seguir, essa relação em Fichte e Schelling a partir de algumas passagens das "Investigações" do próprio Schelling (\$2). Depois analisarei a função do conceito de analogia e

2 Uma tratação da relação entre a filosofia primeira de Schelling e as suas consequências no âmbito da filosofia da religião foi desenvolvida por Olivetti (1974). Olivetti considera a filosofia de Schelling como expressão de uma tendência geral da filosofia idealista e romântica, conforme a qual "a inquieta busca do originariamente idêntico, a insatisfeita exigência de significado, é um tema que se ergue imediatamente da problematização romântica da relação entre indivíduo e universo, que não se esgota na configuração idealista que se põe sob o signo da idealidade" (p. 9). Retomando e aprofundando as teses de Löwith, Olivetti tenta mostrar como a filosofia de Schelling pode ser interpretada como a última tentativa para resolver a relação entre indivíduo e universo no espaço de uma filosofia especulativa do absoluto. $\mathrm{O}$ caminho especulativo de Schelling, que passa da filosofia da identidade à filosofia positiva, demonstra, porém, que uma solução puramente especulativa do problema não seja possível, justamente porque a pura especulação não consegue dar conta do elemento histórico da religião que, quer em Schelling, quer em Hegel, Fichte ou Schleiermacher, apresenta, sem demonstrá-la, a totalização a que a especulação anseia. Olivetti, porém, limita-se em descrever a posição de Schelling, mas não considera, nem histórica, nem teoricamente, a relação entre Fichte e Schelling entre 1809 e 1813. 
de símbolo nesse contexto $(§ 3)$ e, no final, tratarei da diferente compreensão da Igreja como símbolo do absoluto na "Filosofia da arte" de Schelling e na "Ética” fichtiana de 1798 e $1812(\$ 4)$.

\section{A filosofia transcendental e o absoluto}

A definição dos limites e da extensão da filosofia transcendental representa um ponto fundamental sobre o qual Fichte e Schelling consumam a polêmica entre eles. Segundo Fichte, a filosofia transcendental deve elaborar uma análise e uma visão acerca dos princípios do saber. Em Schelling, a filosofia transcendental apresenta-se na forma de uma extensão dos princípios do idealismo na compreensão da natureza. ${ }^{3}$ Schelling sustenta que a filosofia transcendental não pode ser reduzida a um idealismo. Ela é também um realismo que coincide com o idealismo relativo às leis do desenvolvimento do raciocínio filosófico. ${ }^{4}$ Fichte entende que o idealismo é uma compreensão do absoluto a partir de seu reflexo (Reflex) fundamental. Schelling considera que a filosofia transcendental é um desdobramento, paralelo e recíproco, de um ponto de vista reflexivo e do desenvolvimento real da natureza, ou seja, da forma do absoluto (reflexão, subjetividade) e da sua existência (natureza, realidade). A doutrina da ciência tem de se sobrepor ao eu visando a um aprofundamento intensivo da compreensão dos princípios de seus próprios princípios. ${ }^{5} \mathrm{O}$ eu não permanece um sujeito absoluto, mas torna-se uma forma de concretização da razão. A filosofia schellinguiana da identidade esclarece que a sobreposição da subjetividade acontece por meio da postulação de uma unidade indiferente da razão - unidade do real e do ideal - diante da qual a subjetividade não faz sentido se não for posta em relação a outro de si: a natureza. ${ }^{6}$

$\mathrm{Na}$ "Freiheitsschrift", essas questões se encontram com uma problematização ética (relativa à origem do arbítrio e à origem da distinção entre bem e mal) e teológica (relativa à possibilidade do mal em Deus). Para enfrentar essas questões, Fichte utiliza, segundo Schelling, uma unidade abstrata da razão por meio da qual as vontades individuais se juntam numa vontade geral e indiferenciada que, por sua vez, é compreendida como ordem moral do mundo. ${ }^{7}$ Contudo, este conceito não consegue, conforme Schelling, juntar a

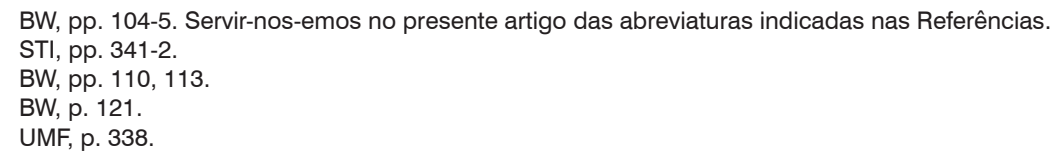


fundamentação da liberdade com a visão dos princípios da natureza. Por causa disso, "a conexão do conceito de liberdade com a visão complexa do mundo continua a ser o objeto de uma investigação necessária" e "a mola inconsciente e invisível atrás de cada tendência para o conhecimento a partir do nível mais baixo", isto é da filosofia. ${ }^{8}$ A visão fichtiana, ainda que tenha uma importância histórica, segundo Schelling, é cheia de falhas e contradições. Fichte, de fato, encontra na vontade o ser originário, que contém todas as determinações que possam ser atribuídas à liberdade (como ausência de fundamento, eternidade, independência, autoafirmação). Mas esta resposta apenas idealista não esgota o fenômeno da liberdade. Com certeza Fichte chega a demonstrar que a atividade do eu, a liberdade e a vida, são o verdadeiro real. Mas daí não surge a demonstração contrária, segundo a qual "todo real (a natureza, o mundo das coisas) tem fundamento na atividade, na vida e na liberdade, ou, em termos fichtianos, que a egoidade é a totalidade e que a totalidade é a egoidade". 9 Em outras palavras, a vontade pura não seria outro, senão o resultado de uma tentativa desajeitada de juntar a imprescindível afirmação da autonomia da vontade dos indivíduos particulares com a exigência de encontrar uma unidade capaz de sintetizar natureza e liberdade. Mas ela representaria uma indevida transferência dos traços de um eu individual à natureza objetiva.

Schelling amplia os resultados da filosofia transcendental por meio de dois gestos. O primeiro pode ser chamado de retórico e programático e tenta satisfazer uma exigência que ocorre em Fichte também. O segundo evidencia o núcleo especulativo do lado retórico. Pelo primeiro gesto, Schelling apresenta a sua filosofia como uma reprise idealista de Spinoza. ${ }^{10}$ Apenas mediante um espinosismo observado e interpretado do ponto de vista idealista é possível reconhecer a unidade do sensível e do espiritual. A filosofia da natureza principia e cumpre a ciência filosófica, chegando a compreender na liberdade "o último ato potencial com o qual toda natureza se transforma na sensação, na inteligência e, enfim, na vontade". ${ }^{11}$ Assim, a filosofia da natureza põe a liberdade como pressuposto essencial do realismo, pois "só quem tem

8 Idem.

9 UMF, p. 351.

10 Sobre a continuidade entre a exigência fichtiana e a reprise schellinguiana, cf. Sandkaulen (2004) e Zöller (2004). Sandkaulen, em especial, destaca a retomada fichtiana de Espinosa nas últimas exposições da doutrina da ciência como instrumento para tentar aproximar o ponto de vista transcendental da doutrina da ciência a uma ontologia vizinha do realismo jacobiano. Sobre a valorização do pensamento de Espinosa na filosofia clássica alemã, cf. Olivetti (1974), que destaca também o papel desempenhado pelos "Discursos sobre a religião" de Schleiermacher, e os capítulos de Walther (1992), para um aprofundamento da perspectiva histórica.

11 UMF, p. 350. 
apreciado o sabor da liberdade pode advertir o desejo de torná-la análoga a todas as coisas, de estendê-la a todo o universo". ${ }^{12}$

Trata-se de compreender como é possível pôr a liberdade como o fundamento do realismo e de definir as condições capazes de tornar tudo (e também o mundo das coisas e da natureza) análogo à liberdade. "Apenas com os princípios de uma verdadeira filosofia da natureza se pode desenvolver a visão que satisfaz completamente nossa questão". ${ }^{13}$ De fato, a filosofia da natureza é capaz de sustentar a distinção entre a essência tal como existe e a essência como fundamento da existência da própria essência no mesmo sentido da Darstellung de 1801.

Deus - o absoluto, a essência - tem o fundamento de sua existência em si mesmo. Mas esse fundamento não é o fundamento de Deus, senão apenas de sua existência, ou seja, de sua natureza. Na medida em que Deus existe, esse fundamento o precede e o justifica. Mas não no sentido que o fundamento seja causa de Deus, mas no da possibilidade da manifestação da sua natureza: como Deus tem em si mesmo o fundamento, ele pode existir. Porém, na medida em que tudo o que existe é o próprio Deus, Deus é o prius do fundamento. De fato, não teria fundamento para alguém "se Deus não existisse $a c t u$ " ${ }^{14}$ Há um fundamento apenas em graça da existência de Deus na forma de uma atividade (ou de um devir imanente) que não tem fundamento nenhum e que tem que ser fundamentado. Este seria o sentido do ablativo absoluto "actu" com que Schelling define a existência de Deus.

O raciocínio schellinguiano sobre a liberdade e o mal depende da legitimidade da afirmação de um ser que precede todo fundamento e toda dualidade. ${ }^{15}$ A essência do fundamento deve, de fato, ser também capaz de dividir a si mesma em dois começos diferentes. Os dois surgem a partir da natureza de Deus, a qual é a "cobiça do eterno-um de parir a si mesmo". Mas um começo gera o intelecto, ou seja, uma força que tende a condensar Deus à sua essência. $\mathrm{O}$ outro produz a separação das forças. No primeiro caso, a cobiça torna-se um desejo, intelecto, vontade e amor. No segundo, a cobiça é tal e, como simples natureza de Deus, é princípio do que é obscuro, irracional e, neste sentido, é princípio do mal.

Mal e bem podem, então, descender de um elemento unitário. Deus, de fato, pode ser compreendido como indiferença entre dois atos diferentes. 
Esses atos são não idênticos, mas, como Schelling escreve, são "ao mesmo modo". ${ }^{16}$ Como atuações de uma única potencialidade os dois estão em relação com a essência de uma maneira idêntica. Os dois começos são, neste sentido, idênticos, e ao mesmo tempo, diferentes, graças a uma idêntica relação com o fundamento originário (Urgrund); numa palavra: são análogos.

Schelling mesmo esclarece essa passagem: a relação entre essência e natureza pode ser compreendida "analogicamente como aquela entre a força de gravidade e a luz na natureza". ${ }^{17}$ Só que, nesse caso, a analogia não tem uma função explicativa, mas envolve a própria constituição ontológica da natureza. As "analogias físicas", que são analisadas em vários lugares das "Investigações" de 1809, determinam, por assim dizer, as variadas fases da ontogênese da subjetividade concreta como potência suprema do desenvolvimento do idealismo e do realismo no mesmo sentido do "System des transzendentalen Idealismus".

Por essa razão, Schelling, que fica muito próximo da tradição da filosofia da linguagem alemã de Böhme a Hamann, ${ }^{18}$ pode afirmar que o mundo se manifesta não apenas como "palavra vivente, como a própria linguagem de Deus, mas também como palavra falada", do mesmo jeito que "na maioria das linguagens a expressão da razão e o discurso são a mesma coisa". ${ }^{19}$ Surgem daí os três níveis do raciocínio de Schelling: a) a concepção do absoluto como indiferença; b) o fato de que essa concepção envolve a constituição ontológica do mundo; c) a inter-relação entre a constituição do mundo e os resultados da exposição científica da relação entre absoluto e manifestação. Tudo isso implica a possibilidade de estabelecer uma analogia - desenvolvida na "Filosofia da arte" - entre o discurso divino e o mundo como expressão dele. ${ }^{20}$ Não é por acaso que Schelling chega a escrever que "cada mineral é um autêntico problema filosófico", ${ }^{21}$ no sentido em que as categorias elaboradas pela filosofia, e que pertencem à explicação especulativa da relação entre princípio e saber, coincidem com as determinações materiais da própria natureza. Então, toda compreensão da natureza destaca a mesma dinâmica da especulação filosófica.

Assim, pelo menos em Schelling, a constituição da realidade como discurso significante, ou seja, a possibilidade de considerar o mundo como 
estruturado linguisticamente, não reflete uma perspectiva antimetafísica, mas se põe acima de uma metafísica realista do absoluto, entendida como extensão e alongamento da filosofia transcendental, em que as leis da constituição do mundo como manifestação do absoluto correspondem às leis lógicas necessárias para a sua compreensão científica e à linguagem que a expõe.

Essa é a tese que Fichte criticará. Já em uma carta a Schelling de dezembro de 1800, Fichte explica que, do ponto de vista da doutrina da ciência, tornar a natureza como um "analogon" do pensamento é o "fundamento dessa e de outras divergências entre nós", é um "erro". De fato, o "eu não pode [...] ser explicado a partir disso". ${ }^{22}$ Ou seja: não é possível definir a constituição da natureza por meio das leis necessárias para a compreensão do eu; ou melhor: toda explicação da natureza tem sempre que ser conduzida indiretamente como explicação da rede de limitações que tornam o eu um sujeito concreto, o qual tem uma relação necessária com a natureza. E, claro, não porque inexiste um ser que fique fora do eu, ${ }^{23}$ mas porque não há ser que não permaneça numa relação com uma subjetividade que o compreende concretamente.

Daí se consegue um horizonte teórico geral e constante das críticas de Fichte a Schelling, que também permanece constante nos anos seguintes. O absoluto não pode ser duplicado, mas "através do seu ser tem esgotado o seu para (Von)". ${ }^{24}$ Em outras palavras, o absoluto não pode sair fora de si. Ele é neste sentido absoluto: está dissolvido de toda relação e, portanto, de toda existência. $\mathrm{O}$ absoluto não expressa, nem possibilita começo nenhum. "Deus não existe, mas existe apenas o seu fenômeno". ${ }^{25}$ Pois "a nossa filosofia é consequente. Não se pode atribuir o ser a ninguém, nem imediatamente, nem mediatamente". ${ }^{26}$ Apenas a reflexão filosófica, que põe o problema da compreensão do absoluto, o leva a existir, mas não enquanto absoluto, mas sim enquanto fenômeno. O ser do fenômeno, porém, é somente uma forma do ser, um ser fora do ser. A sua constituição ontológica deve ser esclarecida mediante o eu como fato absoluto. A explicação desse fato fica na base de toda reflexão sobre o ser e envolve toda compreensão sobre ele. ${ }^{27}$

Segundo Fichte, Schelling postula a existência de um único absoluto. Porém, ao mesmo tempo introduz tacitamente um segundo ser ou, como já vimos, uma repetição do ser por meio de dois começos. Schelling não esclarece 
que essa repetição diz respeito ao fenômeno, à reflexão, à compreensão do ser, mas não alcança o próprio ser, do qual não é possível uma compreensão direta. ${ }^{28} \mathrm{O}$ ser pode ser semantizado, ${ }^{29}$ isto é, problematizado no contexto de uma visão reflexiva. Porém, essa problematização transforma o ser na lei do saber que observa a si mesmo e exprime a estrutura essencial de referência ao outro de si, sem poder afirmar nada sobre a constituição do que sabe no saber.

Essa argumentação, que Fichte desenvolve contra Spinoza, mas que pode a fortiori funcionar contra Schelling, ${ }^{30}$ revela a dimensão tipicamente transcendental e recursiva da doutrina da ciência. ${ }^{31} \mathrm{Na}$ doutrina da ciência, de fato, não há afirmações sobre o ser que sejam diferentes da justificativa mesma de haver uma afirmação sobre o ser. A demonstração da existência não acontece com respeito ao próprio ser, mas em relação à sua manifestação. A existência do fenômeno não pode ser observada no processo da constituição histórica e linguística da natureza senão focando a atenção para uma operabilidade geral da razão, que, por sua vez, não justifica a natureza, mas as condições para sua compreensão de um ponto de vista transcendental. Portanto, Fichte considera a natureza não como Folge (consequência) do absoluto, mas como reflexibilidade (Reflexibilität) do saber como imagem dele.

Sobre essa base, Fichte nega tanto a possibilidade de estabelecer uma analogia entre o saber e a natureza, como aquela de considerar a natureza como algo que está estruturado linguisticamente. A linguagem, de fato, é considerada como um organismo, característica fundamental do qual é a designação simbólica do mundo suprassensível. Uma linguagem, então, é tão desenvolvida, quanto mais é capaz de expressar uma correspondência entre a referência empírica da designação linguística e o significado inteligível dela; ou seja, na medida em que é capaz de esclarecer a designação empírica como reflexo de uma lei que não é empírica. ${ }^{32}$ Também a linguagem que Fichte emprega na exposição da doutrina da ciência não tem que ser uma expressão analógica de um discurso (Rede) feito para um absoluto pessoal, mas indica as habilidades simbólicas de quem constrói e ensina a própria doutrina da ciência, isto é, o Wissenschaftslehrer. A função dele, de fato, deve ser aquela de elevar os seus alunos ao ponto de vista transcendental por meio de símbolos,

28 WL/11, pp. 31-35.

29 Para um esclarecimento dessa expressão, cf. Ivaldo (2003), que lê o percurso da doutrina da ciência como uma definição das condições de possibilidade para formular um discurso sobre o ser, ainda que seja um discurso formulado no âmbito do fenômeno.

30 Esta interpretação de Espinosa como um Schelling disfarçado foi sugerida por Ivaldo (1988).

31 Sobre a recursividade da doutrina da ciência, cf. Bertinetto (2007), que compreende a doutrina da ciência como discurso que visa justificar e legitimar a si mesmo por meio da compreensão dos seus pressupostos.

32 RDN, p. 320. 
analogias e metáforas, que são empregadas para dobrar as determinações de uma língua natural ao novo mundo aberto pela filosofia transcendental. ${ }^{33}$ Claro que aqui não fica implícita só a tradição da filosofia da linguagem alemã (Böhme, Hamann, Herder); pode-se encontrar também Jacobi. Este, embora concordasse com Hamann e com a sua concepção do mundo como palavra divina, considera inevitável a dimensão abstrata e instrumental da linguagem. ${ }^{34}$ Ao mesmo tempo, a compreensão fichtiana da linguagem é condicionada pelas teorias transcendentais que foram formuladas por Bernhardi nos primeiros anos do século XIX segundo os princípios da doutrina da ciência. ${ }^{35}$ Uma vez que Fichte poderia ficar longe das sugestões do Linguistic turn, a sua concepção instrumental da linguagem parece mais coerente com o projeto de uma filosofia transcendental. De fato, a teoria fichtiana do absoluto ficaria longe de um realismo metafísico que tende a compreender o absoluto como um ser que existe realmente e que fica fechado em si mesmo, mas muito próximo a um modelo teórico que, na problematização do absoluto, torna-se consciente das suas potencialidades práticas. ${ }^{36}$

Essa primeira série de considerações evidencia, além disso, uma diferente função da analogia em Fichte e Schelling. Segundo Schelling, analógica é a relação metafísica entre absoluto e manifestação. Ora, a relação analógica determina também as maneiras pelas quais a manifestação se articula na história. Em Fichte, pelo contrário, o recurso à analogia tem uma função instrumental e ela é empregada na reconfiguração da relação entre a manifestação e si mesma como uma operabilidade geral da razão, a partir da qual é, então, possível olhar a manifestação como imagem do absoluto. Nesse sentido, a visão de Schelling e aquela de Fichte são especulares. O discurso de Schelling sobre a dimensão simbólica da finitude é condicionado pela analogia. Em Fichte, as potencialidades analógicas da linguagem ficam condicionadas pela própria estrutura da razão, enquanto apresentação fenomênica do absoluto que tem que compreender a si mesma enquanto tal.

$33 \mathrm{WL} / 11$, p. 18

34 Sobre isso, cf. Olivetti (1970).

35 Bernhardi (1801) e Bernhardi (1805). Sobre Bernhardi e a filosofia transcendental, veja Perconti (1999), que, todavia, não trata da relação entre Bernhardi e Fichte.

36 Essa é a tese de Olivetti (1992, p. 85), que interpreta a filosofia da linguagem envolvida na doutrina da ciência de Fichte como consequência da dimensão originariamente intersubjetiva da consciência concreta. 


\section{Simbolizações do absoluto}

A concepção da linguagem proposta por Fichte não tem, então, o mesmo significado especulativo daquela de Schelling. De fato, Fichte explica a função da linguagem na construção da doutrina da ciência no contexto da definição da "Kunst des Philosophierens" ( $a$ arte de filosofar). A arte de filosofar abarca o conjunto dos requisitos necessários para acessar a perspectiva da doutrina da ciência. Schelling foca isso nas "Lições sobre o método de estudo acadêmico". Porém, em Fichte a linguagem tem uma função heurística e simbólica. Em Schelling, a linguagem está em relação com o descer ao tempo das ideias eternas. Em Fichte, a língua natural e a tradição exprimem a necessidade de inventar novas palavras e uma nova língua capazes de exprimir os progressos da filosofia.${ }^{37}$ Em Schelling, ao contrário, a tradição é o reflexo de uma queda e de uma historicização do absoluto. ${ }^{38}$

Tudo isso parece evidente quando se considera que a concepção do símbolo, da analogia e da metáfora, que Fichte desenvolve a partir de 1810, é muito mais limitada do que a schellinguiana e, em especial, aquela da "Filosofia da arte", de Schelling.

Em Fichte, as metáforas, as analogias e os símbolos têm a função de tornar possível a passagem entre o saber comum e o saber completamente novo que pode ser obtido na perspectiva transcendental. O conhecimento científico, como o das regras e das leis da conexão do fenômeno com a sua causa, envolve um emprego da linguagem capaz de acionar uma dinâmica que produz conexões que fazem sentido sem ter uma referência aos objetos que existem de fato. ${ }^{39}$ Com efeito, a linguagem expositiva da doutrina da ciência é uma linguagem figurada ou, nas palavras de Fichte, uma linguagem simbólica (sinnbildlich). ${ }^{40}$

O emprego simbólico da linguagem caracteriza, em primeiro lugar, a atividade do professor (Wissenschaftslehrer), o qual habilita os alunos por meio do emprego de construções linguísticas particulares que são capazes de mediar o complexo de conhecimentos oferecido pela consciência comum e o nível suprassensível da doutrina da ciência, a qual, num contexto de relações puras, representa o terminus ad quem da formação científica. Um autêntico professor da doutrina da ciência (Wissenschaftslehrer) deve ser capaz de produzir "metáforas viventes". Ele tem que ter um domínio da linguagem 
que possibilita uma exposição dos conteúdos da doutrina da ciência capaz de sempre tocar diferentes alunos. ${ }^{41}$ Nesse sentido, Fichte aproxima-se da tradição da retórica antiga; suas metáforas correspondem ao esquema próprio da analogia proportionalis que pode ser expresso na fórmula $\mathrm{A}: \mathrm{B}=\mathrm{C}: \mathrm{X} .{ }^{42}$

Do ponto de vista de quem tem que apreender a doutrina da ciência, o emprego simbólico da linguagem solicita uma reflexão sobre o dado empírico e uma consideração crítica dessa própria reflexão. A recepção produtiva das expressões simbólicas da doutrina da ciência exige um exercício e uma atenção para as conexões entre a representação e os fenômenos. ${ }^{43}$ A construção de novas conexões entre complexos de implicações conhecidos representa o instrumento principal para conseguir os objetivos da compreensão: não se trata da compreensão de fenômenos determinados, mas consiste em apreender as regras da multiplicidade fenomênica que não tem que ser necessariamente percebida. A figuração linguística não implica só a extensão ou a repetição mecânica de esquemas epistemológicos notórios. Ela exige, antes, que quem acolhe a expressão figurada troque as estruturas fundamentais do próprio conhecimento, passando de um conhecimento já obtido a um conhecimento completamente novo.

A expressão figurada, na verdade, não poderia ser traduzida num conjunto de proposições que têm um significado literal. Nem o aumento do conhecimento que surge por meio da expressão figurada pode ser reconduzido a uma relação unilateral entre os complexos de implicações das palavras que a constituem. O sucesso das analogias do Wissenschaftslehrer exige a cooperação do aluno. Esse aluno tem que intuir o que há de "ressoado" nas expressões do próprio Wissenschaftslehrer e tem que se dispor, dessa maneira, a acessar a "densidade" das implicações que definem a dinâmica simbólica presente na expressão figurada. ${ }^{44} \mathrm{O}$ aluno não é passivo, nem fica paralisado por causa da expressão figurada da qual recebe as sugestões. Ele compreende concretamente a figuração linguística apenas quando se torna capaz de "fazer algo" de novo a respeito da consciência ordinária e em razão da expressão figurada; ou, como Fichte escreve na WL/11, no momento em que ele sabe "aplicar" a intuição que surge a partir da própria figuração linguística.

O aumento do conhecimento provocado pela simbolização linguística não consiste, portanto, numa extensão do conhecimento, mas na capacidade de

42 Sobre isso e, mais em geral, sobre o emprego fichtiano da analogia, cf. Österreich-Traub (2006, pp. 93-95).

43 GA, IV, 4, p. 22.

44 Os conceitos de "ressonância" e "densidade" são empregados no sentido de Black (1983, pp. 97-135). 
empregar de uma maneira diferente os esquemas epistemológicos adquiridos. Nessa capacidade de fazer algo diferentemente, consiste a autêntica "descoberta" exigida para o aluno da doutrina da ciência. O progresso do conhecimento implícito no emprego figurativo da linguagem consiste na capacidade de experimentar, ou seja, de formular hipóteses que permitiriam a compreensão de uma maneira legítima sobre os fenômenos que não são vinculados a um dado da percepção; ${ }^{45} \mathrm{e}$ isso na medida em que a linguagem figurada descreve as coisas, mas não consiste numa asserção sobre os fatos.

Nesse contexto, torna-se possível diferenciar o emprego fichtiano das diferentes figuras retóricas: a dimensão simbólica geral da linguagem permite formular metáforas e, a partir destas, estabelecer analogias entre o que se percebe empiricamente e o que não é empírico e que deve ser evidenciado pela doutrina da ciência.

A interpretação do mesmo problema, oferecida por Schelling na "Filosofia da arte", é diferente. Pode ser mais complexa e não fica restrita a uma compreensão dos diferentes níveis ou dos possíveis empregos da linguagem ordinária. Schelling investiga, de fato, a relação entre filosofia, linguagem, arte e religião. No $\$ 39$ da "Philosophie der Kunst", a linguagem é somente uma modalidade possível de articular simbolicamente o finito, mas não esgota completamente o próprio horizonte do simbólico, que tem compreendido como capacidade de representar o absoluto como indiferença entre particular e geral. ${ }^{46}$ Mesmo essa representação, que em Schelling é chamada de mitologia, é diferenciada da linguagem comum e se torna uma "linguagem superior" que fornece a matéria seja à filosofia, seja à arte. ${ }^{47}$

A linguagem é um esquema, ou seja, uma expressão de determinações particulares do pensamento que pode ser efetuada pelo emprego de signos gerais. ${ }^{48} \mathrm{O}$ esquema deve ser distinguido da alegoria, em que o particular exprime uma referência constante para o geral e é absorvido no próprio geral. ${ }^{49} \mathrm{O}$ esquema e a alegoria têm que ser, além disso, diferentes do símbolo. É aí que geral e particular coincidem. A imagem alegórica diferencia-se do original somente na medida em que não tem a mesma determinação espacial do próprio original. ${ }^{50}$

45 GA IV, 2, p. 23.

46 PK, p. 54.

47 PK, p. 56. Para uma apresentação detalhada da função e do desenvolvimento da mitologia em Schelling, cf. Curtine (2007).

48 PK, p. 56.

49 PK, p. 55.

50 Na medida em que esquema, símbolo e alegoria, representam três diferentes formas da imaginação, é possível estabelecer entre eles uma Stufenfolge que reflete as articulações do pensamento e, ao 
A concepção schellinguiana do absoluto como ponto de indiferença entre dois começos que podem ser articulados na história não é compatível com a possibilidade de considerar alegoria, símbolo e esquema como três figuras retóricas equivalentes, nem como três momentos diferentes de um progresso linear; nem, enfim, como três especificações da constituição transcendental do sujeito representante. Elas são, mais propriamente, três articulações diferentes da manifestação do absoluto. O símbolo, que em Fichte foi a base para formar a doutrina da ciência e uma indicação da abertura da razão teórica num horizonte prático, torna-se, em Schelling, uma expressão da impossibilidade de uma representação realizada da integração e da reciprocidade do dado histórico e do raciocínio especulativo, do particular e do geral, do finito e do infinito, que é necessária para sustentar uma concepção do absoluto como indiferença. $\mathrm{O}$ símbolo caracteriza a arte e a religião grega, em que o geral já é o particular; o finito coincide com o infinito e o presente coincide com o passado e o futuro. Se, num primeiro momento, o símbolo pode ser interpretado como síntese do esquema e da alegoria, agora o símbolo contrapõe-se a eles. Esquema e alegoria são, de fato, capazes de exprimir melhor a distinção e a separação entre finito e infinito, e a estrutura essencialmente referencial do finito. Mas a significação típica do esquema não é suficiente para refletir a complexidade da mitologia. O esquema articula o geral como propriedade de um indivíduo, o qual, aplicando o esquema, realiza o particular. No caso da alegoria, ao contrário, o processo é o inverso. A representação particular é alegórica, remete a além de si, e tende a se anular no que ela significa. $\mathrm{O}$ esquema exprime uma ação poiética, ou seja, uma ideia que é realizada num produto exterior. A alegoria exprime uma praxis, isto é, uma ação que visa para um terminus ad quem que nunca pode ser realizado; nesse sentido, a alegoria se esgota nesse próprio pôr.

Há duas consequências interessantes nesse raciocínio. A primeira envolve a preeminência do símbolo; embora ele mantenha uma preeminência lógica e transcendental, o símbolo é subordinado ao esquema e à alegoria de acordo com as suas potencialidades representativas. Schelling deve restringir sua concepção da linguagem como símbolo e substituir essa concepção por um conceito de mitologia como linguagem superior que privilegia a alegoria - o que parece mais coerente com uma compreensão do absoluto como

mesmo tempo, as da natureza e das relações entre o eu e o mundo. O pensamento em si mesmo já é esquematizante, o agir é alegórico, a arte é simbólica. Uma mesma distinção é válida para a ciência (dividida em aritmética, geometria e filosofia), para a arte (música, pintura, plástica) e para a poesia (dividida em lírica, épica e dramática). 
indiferença. A segunda consequência envolve o problema da relação entre história e absoluto. A "filosofia da identidade" não pode se limitar a uma representação geral do absoluto (o que segundo Schelling é a representação filosófica) como indiferença do geral e do particular. É preciso produzir uma representação dessa indiferença no próprio particular, que é compreendido como concretização histórica de uma ideia. De maneira mais específica, a concepção schellinguiana implica uma valorização da representação do absoluto em que história e especulação vão coincidir ou, melhor, daquela representação em que o absoluto é intuído como história: o cristianismo cuja natureza é precisamente alegórica. ${ }^{51}$

Então, ao passo que Fichte aprofunda os princípios do saber na doutrina da ciência por meio de uma concepção da linguagem como abertura essencial do finito (do saber factual) à sua razão não empírica - o que é evidenciado de uma maneira específica na flexibilidade das exposições da doutrina da ciência -, em Schelling a tentativa de uma radicalização da filosofia da natureza numa filosofia da identidade envolve uma "simbologia do absoluto" e encerra o processo de significação do absoluto numa concepção da história como totalidade das manifestações de um único núcleo especulativo. Essa importante divergência entre o projeto fichtiano e o de Schelling vai afetar a compreensão da igreja como lugar em que o absoluto se manifesta como símbolo. Assim, desenvolverei as implicações filosófico-religiosas da divergência estética e especulativa que caracteriza o trabalho dos dois autores.

\section{Igreja e símbolo}

A valorização da história é imanente ao desenvolvimento especulativo da filosofia de Schelling, também de um ponto de vista metodológico. A "construção" de um fenômeno como manifestação do absoluto, de fato, é acrescida à "apresentação da unidade do geral e do particular" 52 e pode ser efetuada tanto mostrando como em cada particular está presente uma mesma forma absoluta (por exemplo, o puro espaço na construção de uma figura geométrica), como mostrando que o universal de cada unidade particular (como, por exemplo, um triângulo em si em relação a um triângulo particular) é o mesmo do particular (e então cada triângulo particular perante todos os triângulos particulares). Não é difícil interpretar esse conceito como uma repetição da distinção, típica da "Filosofia da arte", entre símbolo (conceito 
geral de construção) e alegoria (particular que é refutado em seu significado geral). Por essa razão, o cristianismo pode ser descrito por meio de uma "construção histórica". No cristianismo, de fato, a manifestação particular do absoluto significa o geral como unidade de particular e geral.

Como já foi dito, no cristianismo a intuição do universal e a do universal como processo histórico coincidem. Além disso, o fato de que a intuição cristã da história estabelece unicamente sua direção, deixando indefinida sua realização, torna o cristianismo tipicamente alegórico: ele é expressão de uma referência infinita do significante ao significado que não vai cumprir o próprio processo de significação. ${ }^{53}$

O cristianismo, stricto sensu, não tem símbolos, mas ações simbólicas, ou seja, representações cujo conteúdo é um agir que manifesta a ligação entre um fato histórico-concreto e a sua essência. $\mathrm{O}$ agir revelado na intuição cristã da história manifesta-se como uma obra de arte viva, um drama espiritual no qual todo mundo participa. ${ }^{54} \mathrm{~A}$ comunidade evidenciada nessa dinâmica é a Igreja. Ela é, em geral, símbolo e, em particular, alegoria do absoluto. É no culto que é expressa a característica simbólica da comunidade da Igreja e, na medida em que no agir inteiro da comunidade da Igreja é o reino de Deus que é manifestado como reino visível, a potencialidade simbólica da Igreja implica que sua estrutura seja hierárquica. Numa palavra, a Igreja, cuja característica geral é aquela de ser símbolo vivo do reino de Deus, tende para o catolicismo: uma entidade hierárquica, totalizante e representativa de um processo de significação infinita. ${ }^{55}$ Não é por acaso que Schelling considera a Igreja como símbolo e não imediatamente como alegoria. A Igreja, de fato, não é a resolução de símbolos que já existem, mas o horizonte que permite às ações particulares terem um significado, ou seja, existirem como alegorias; mais propriamente, serem assumidas no reino da significação. ${ }^{56}$

O significado histórico-especulativo que Schelling atribui ao catolicismo não pode ficar mais distante do tratamento fichtiano da relação entre símbolo e Igreja. Ao "papismo" da Igreja católica, ${ }^{57}$ Fichte contrapõe o protestantismo, que é capaz de compreender o símbolo como abertura do finito à sua infinita razão prático-teórica e, nesse sentido, como representação da ligação entre sensível e suprassensível. Em Schelling, pelo contrário, o símbolo é a expressão histórico-concreta da manifestação do absoluto na mitologia; em Fichte, 
o símbolo é coerente com sua concepção da linguagem. O símbolo é uma construção que reflete, com certeza, a concretude histórica do gênero humano, mas ele é, ao mesmo tempo, expressão de uma constante perfectibilidade, tanto de si mesmo como expressão linguística e representativa, como do que é representado nessa representação, ou seja, da manifestação da ideia ética no mundo sensível.

Se em Schelling a estrutura simbólica da Igreja manifesta uma relação específica entre particular e geral, em Fichte o símbolo exprime um grau mínimo de moralidade e de racionalidade, que são necessários a fim de que "todos possam condicionar a moralidade de todos; em primeiro lugar em relação à sua ação [...] e, depois, sobre a sua convicção e visão". ${ }^{58} \mathrm{Na}$ "Sittenlehre" fichtiana, de 1798, trata-se de um dever particular do sujeito concreto. Nas lições de 1812 a mesma exigência é integrada na fenomenologia da "Ética", ou seja, no percurso que define as condições de possibilidade da manifestação da ideia ética num agir individual. Para tanto, o símbolo, embora tenha uma raiz histórica, reflete a entrada da ideia ética no mundo sensível por meio de "espíritos geniais", que pela primeira vez conseguem exprimir em representações o próprio ideal ético, ${ }^{59}$ e aperfeiçoada para "espíritos simbólicos", ${ }^{60}$ cuja tarefa é tornar sempre mais coerente a representação simbólica e a própria ideia ética que deve ser encarnada por todos.

Em relação a esse ponto, o símbolo difere da revelação. A revelação apresenta-se, de fato, como algo que pela primeira vez existe por meio do conceito, a qual tem que ser comunicada a uma pessoa singular por uma linguagem ainda desconhecida. O símbolo, ao contrário, é algo que mantém unida uma comunidade, ou melhor, é a condição de possibilidade da manifestação de Deus num horizonte comunitário. ${ }^{61} \mathrm{~A}$ revelação, em contrapartida, é uma manifestação concreta e factual mediante a visibilidade, a compreensibilidade e a comunicação dessa manifestação.

Daí deriva uma complicação da relação entre moralidade e religião. É verdade que, em Fichte, existe uma identificação entre moralidade e religião. O símbolo e a revelação são modos pelos quais a ideia ética se manifesta como imagem de Deus. Mas essa identificação é paralela à afirmação de um destino religioso da moralidade. A ação ética é, de fato, aprofundada a uma intenção ético-religiosa que pressupõe uma fé em Deus como ordem moral do 
mundo. ${ }^{62}$ Então, não seria um erro falar de um destino cristológico da doutrina da ciência, pois a compreensão das manifestações da liberdade "exige para si mesma a encarnação concreta de uma liberdade que esteja unida à sua própria destinação. Essa encarnação é, segundo Fichte, Jesus". ${ }^{3}$

Assim, enquanto o fato da encarnação já é uma ação que permite exercitar a moralidade reforçando a convicção de todas as pessoas por meio de uma ação concreta, como Fichte já sustentava no escrito de 1791, "Sobre as intenções da morte de Jesus", o símbolo promove a moralidade na medida em que comunica uma exigência e, nesse sentido, torna possível a participação de um conjunto de indivíduos na realização de um fim comum que coincide com o fato realizado na revelação. Daí deriva que a formação da Igreja corresponde bem mais a uma formação histórica do que a uma possibilidade permanente de uma comunidade cujo fundamento está na estrutura transcendental do eu como imagem do absoluto.

Não é por acaso, então, que a descrição fichtiana recupera algumas formas argumentativas das exposições da doutrina da ciência: a estrutura simbólica envolvida em cada comunicação linguística e representativa sempre permite mais determinações metafóricas e analógicas capazes de manifestar numa maneira assentida, e sempre mais coerente, o significado implícito no símbolo. Então, é sempre possível que uma comunidade seja formada por meio de um símbolo, cuja estrutura representativa não é dada, mas formada e renovada pelo próprio juntar e formar da comunidade. O fato de que, segundo Fichte, essa seja uma característica da religião protestante, e que o protestantismo seja mais coerente com o nível em que chega a modernidade, pode ser demonstrado numa análise das conexões entre as formas representativas do cristianismo e as estruturas históricas, antropológicas, teológicas e especulativas que as condicionam. ${ }^{64}$

Porém, Schelling já confirma tudo isso ao escrever que "o espírito da época moderna tende evidentemente a anular todas as formas simplesmente finitas", ${ }^{65}$ e que "o protestantismo não poderia criar uma união positiva, nem

62 Cf. Ghia (2003, pp. 79-80), que destaca esta dinâmica como o movimento fundamental da filosofia da religião de Fichte no seu entrelaçamento com a ética.

63 Ivaldo (2000, pp. 133-134).

64 Cf. Olivetti (1967). Olivetti reconduz a diferença entre protestantismo e catolicismo justamente a uma maneira diferente de compreender a relação entre história e especulação. Ao passo que no protestantismo a liberdade tem uma função central, atestando uma prevalência da dimensão especulativa e subjetiva sobre a histórica, no catolicismo a afirmação da liberdade fica subordinada à representação, isto é, a um elemento histórico que não pode ser recuado. Não apenas o desenvolvimento da filosofia moderna, mas o da arte e o da arquitetura sacra também ficam caracterizados por esta tensão (cf. por ex. p. 107).

65 VAS, p. 200. 
uma manifestação simbólica exterior na forma de uma igreja". ${ }^{66}$ É verdade que o catolicismo se torna muito mais coerente com a dimensão alegórica da relação entre finito e infinito. Mas a significação infinita da alegoria não anula o problema da relação entre o absoluto e a sua dimensão histórica que é expressa pelo cristianismo. E isto significa que as categorias estéticas e linguísticas empregadas por Schelling não são mais suficientes nem ao desenvolvimento da filosofia primeira, que no começo do século XIX não pode parar na simetria do histórico e do especulativo, nem na filosofia da religião, pois nesse nível a relação entre religião histórica e religião absoluta não pode ser resolvida e dissolvida. A dimensão católica da Igreja põe o problema da totalização da história no absoluto, mas não anula a tensão entre o absoluto e a história.

O fato de que, para justificar o discurso de Schelling, seja necessária a justificativa da relação entre história e absoluto, e que essa justificativa pode se dar no espaço de um saber que deve ser compreendido em seus princípios, parece algo inevitável a ser realizado. E parece inevitável também o perigo de se fechar numa filosofia transcendental à la Fichte. ${ }^{67}$ Mas Schelling também poderia realizar um percurso alternativo, ou seja, aquele da "Filosofia da revelação", em que há uma forte tentativa de reduzir o especulativo ao âmbito histórico, isto é, a um aniquilamento da tensão entre esses dois elementos. A demonstração de uma tentativa desse tipo, que fica na base da dissolução pósidealista do problema da religião absoluta e, por conseguinte, da possibilidade de refletir sobre o triunfo do significado realizado, ou da identidade, ou da autotransparência do espírito, não faz parte deste trabalho. ${ }^{68}$ Aqui é suficiente que se tenha demonstrado como a polêmica entre Fichte e Schelling não diz respeito somente às questões de princípio, mas também às diversas dimensões do desenvolvimento sistemático do pensamento desses autores. Assim, foram apresentados os instrumentos que ambos empregam para realizar seus projetos filosóficos, e, sobretudo, suas reflexões sobre o cumprimento das suas propostas.

66 Idem.

67 Este perigo está assinalado com muita clareza por Olivetti (1967, p. 287).

68 Cf. Olivetti (1974, p. 22), que alega que a Filosofia da revelação fica já para além da tensão entre história e especulação, destacando o fracasso do chamado "idealismo alemão". 


\section{Abreviações}

\section{Fichte}

GA $=$ "Johann Gottlieb Fichtes Gesamtausgabe der Bayerischen Akademie der Wissenschaften”. Ed. R. Lauth, H. Jacob, H. Gliwitzky. Stuttgart-Bad Cannstatt: Fromman-Holzboog, 1962-. I, Werke; II, Nachgelassene Werke; III, Cartas; IV, Nachschriften.

RDN = "Reden an die deutsche Nation". In I.E. Fichte (Ed.). Fichtes Werke, vol. VII. Berlin: de Gruyter, 1971.

SL/12 = "Sittenlehre 1812". GA II, 13.

SL/98 = "Das System der Sittenlehre nach den Principien der Wissenschaftslehre". Ed. H. J. Verweyen. Hamburg: Meiner, 1995.

WL/10 = "Wissenschaftslehre 1810". Ed. H.G. von Manz: Die späten Wissenschaftlichen Vorlesungen, T. I. (1809-1811). Stuttgart-Bad Cannstatt: Fromman-Holzboog, 2000.

WL/11 = "Wissenschaftslehre 1811". Ed. G. Rametta. Milano: Guerini, 1999.

\section{Schelling}

BW = "Fichte-Schelling Carteggio e scritti polemici". Ed. F. Moiso. Milano: Guerini, 1989.

PK = "Philosophie der Kunst". In: O. Weiss (ed.). F.W.J. Schelling, Werke. Auswahl in drei Bänden, Vol. 3. Leipzig: Eckardt, 1907.

STI = "System des transzendentalen Idealismus". In: K.F.A. Schelling (ed.). Schellings sämmtliche Werke, Vol. 3. Stuttgart-Augsburg: Cotta 1860.

$\mathrm{UMF}=$ "Philosophische Untersuchungen über die menschliche Freiheit". In: K.F.A. Schelling (ed.) Schellings sämmtliche Werke, Vol. 7. Stuttgart-Augsburg: Cotta, 1860.

VAS = "Vorlesungen über das akademische Studium". Stuttgart: Cotta, 1813.

\section{Referências}

BÄR, J. A. "Sprachreflexion der deutschen Frühromantik: Konzepte zwischen Universalpoesie und Grammatischem Kosmopolitismus". Berlin: de Gruyter, 1999. 
BERNHARDI, A. F. "Sprachlehre”. Berlin: Frölich, 1801. "Anfangsgründe der Sprachwissenschaft". Berlin: Frölich, 1805.

BERTINETTO, A. "Genèse et récursivité: la déduction des catégories dans la Doctrine de la Science 1805 de J.G. Fichte”. Révue de Métaphisique et de Morale, 2007, pp. 521-553.

BLACK, M. "Ancora sulla metafora”. In: M. Black, Modelli, Archetipi, Metafore. Tradução para A. Almansi e E. Pradisi. Parma: Pratiche, 1983.

CURTINE, J. F. "La Philosphie Schellingienne de la religion. Staut et vérité de la mythologie". Archivio di Filosofia, Nr. 1-2, pp. 113-136, 2007.

FICHTE, J. G. "Gesamtausgabe der Bayerischen Akademie der Wissenschaften". Ed. R. Lauth, H. Jacob, H. Gliwitzky. Stuttgart-Bad Cannstatt: Fromman-Holzboog, 1962-. I, Werke; II, Nachgelassene Werke; III, Cartas; IV, Nachschriften.

. "Fichtes Werke". Ed. I. E. Fichte. Berlin: de Gruyter, 1971.

. "Das System der Sittenlehre nach den Principien der Wissenschaftslehre".

Coord. para H. J. Verweyen, Hamburg, Meiner, 1995.

1999.

. "Dottrina della scienza 1811". Tradução de G. Rametta. Milano: Guerini,

. "Die späten wissenschaftlichen Vorlesungen”. Vol. 1. (1809-1811). StuttgartBad Cannstatt: Fromman-Holzboog, 2000.

GHIA, G. "Fichte nella teologia. Dall'Atheismusstreit ai nostri giorni”. Milano: Guerini, 2003.

IVALDO, M. "La comprensione fichtiana di Spinoza". In: Filosofia, 1988, pp. 285313.

. "Johann Gottlieb Fichte. Gesù 'punto fondamentale e punto di unità della storia'(Staatslehre 1813)”. In: S. Zucal (ed.). Cristo nella filosofia contemporanea I. Da Kant a Nietzsche. Cinisello Balsamo: San Paolo, 2000. pp. 129-158.

"Philosophie trascendentale et ontologie dans la WL de 1811". In: J. Ch. Goddard e M. Messchalck (ed.). Fichte. La philosophie de la maturité. Paris: Vrin, 2003. pp. 41-54.

MOISO, F. (ed.). "Fichte-Schelling. Carteggio e scritti polemici”. Milano: Guerini, 1989.

OLIVETTI, M. M. "Il tempio. Simbolo cosmico". Roma: Abete, 1967. . "L'esito teologico della filosofia del linguaggio di F.H. Jacobi". Padova: CEDAM, 1970.

."Filosofia della religione come problema storico. Romanticismo e idealismo romantico". Padova: CEDAM, 1974.

. "Analogia del soggetto". Roma: Laterza, 1992.

ÖSTERREICH, P.L.-TRAUB, H. "Der ganze Fichte”. Stuttgart: Cotta, 2006.

PERCONTI, P. "Costruire ponti con l'immaginazione. I. Kant e A.F. Bernhardi". In: L. Formigari (coord.). Imago in phantasia deposita. Studi sulla teoria dell'immaginazione. Roma: Carocci, 1999. pp. 303-317. 
SANDKAULEN, B. "Spinoza zur Einführung. Fichtes Wissenschaftslehre von 1812". Fichte-Studien, pp. 37-52, 2004.

SCHELLING, F. W. J. "Vorlesungen über das akademische Studium". Stuttgart: Cotta, 1813.

. "Philosophische Untersuchungen über die menschliche Freiheit". In: K.F.A. Schelling (Ed.). Schellings sämmtliche Werke, Vol. 7. Stuttgart-Augsburg: Cotta, 1860a.

. "System des transzendentalen Idealismus". In: K.F.A. Schelling (ed.). Schellings sämmtliche Werke, Vol. 3. Stuttgart-Augsburg: Cotta, 1860b. . "Philosophie der Kunst". In: O. Weiss (ed.). F.W.J. Schelling, Werke. Auswahl in drei Bänden, Bd. III. Leipzig: Eckardt, 1907.

WALTHER, M. (coord.). "Spinoza und des deutschen Idealismus". Würzburg: Königshausen u Neumann, 1992.

ZÖLLER, G. "Das Absolute und seine Erscheinung. Die Schelling Rezeption des späten Fichte". Internationales Jahrbuch des deutschen Idealismus, pp. 165-182, 2003.

. "Fichte als Spinoza, Spinoza als Fichte. Jacobi über den Spinozismus der Wissenschaftslehre". In: B. Sandkaulen (coord.). Friedrich Heinrich Jacobi. Ein Wendepunkt der geistigen Bildung der Zeit. Hamburg: Meiner, 2004. pp. 37-52. 